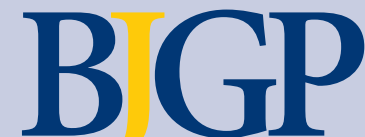

EDITOR

Roger Jones, DM, FRCP, FRCGP, FMedSci London

DEPUTY EDITOR

Alec Logan, FRCGP

Motherwell

JOURNAL MANAGER

Catharine Hull

SENIOR ASSISTANT EDITOR

Erika Niesner

ASSISTANT EDITOR

Moira Davies-Cinar

EDITORIAL ASSISTANT

Tania Marszalek

ADVERTISING EXECUTIVE

Brenda Laurent

EDITORIAL BOARD

Richard Baker, MD, FRCGP

Leicester

Stephen Barclay, MD, FRCGP, DRCOG

Cambridge

Chris Butler, MD, MRCGP

Cardiff

Kath Checkland, PhD, MRCGP

Manchester

Mark Gabbay, MD, FRCGP

Liverpool

Clare Gerada, MBE, FRCGP, MRCPsych

London

Murray Lough, MD, FRCGP

Glasgow

David Mant, MD, FRCGP, FMedSci

Oxford

Tim Peters, MSc, PhD, CStat, FFPH

Bristol

Chris Salisbury, MD FRCGP

Bristol

John Sandars, MSc, MD, FRCGP, MRCP

Leeds

Mark Shapley, FRCGP, DCH, DRCOG

Newcastle-under-Lyme

Niroshan Siriwardena, MMedSci, PhD,

FRCGP

Lincoln

Theo Verheij, MD, PhD, MRcGP

Utrecht, The Netherlands

Sue Wilson, BA, PhD, PGA

Birmingham

2008 impact factor: 2.278

EDITORIAL OFFICE

14 Princes Gate, London SW7 1PU

(Tel: 0207581 3232, Fax: 0207584 6716).

E-mail: journal@rcgp.org.uk

http://www.rcgp.org.uk/bjgp

PUBLISHED BY

The Royal College of General Practitioners,

14 Princes Gate, London SW7 1PU. Registered charity number 223106. The BJGP is published by the RCGP, but has complete editorial

independence. Opinions expressed in the BJGP should not be taken to represent the policy of

the RCGP unless this is specifically stated.

No endorsement of any advertisement is implied or intended by the RCGP.

PRINTED IN GREAT BRITAIN BY

HPM Limited, Prime House, Park 2000,

Heighington Lane Business Park,

Newton Aycliffe, Co. Durham DL5 6AR.

Printed on $100 \%$ recycled paper

\title{
July Focus
}

\section{EVIDENCE AND THE CONSULTATION}

Thirty years ago Stott and Davies described a structure for the content and conduct of the general practice consultation. ${ }^{1}$ This consists of four interconnected topics and tasks understanding and dealing with the acute, presenting problem, attending when appropriate to comorbidity and other chronic medical problems, incorporating health promotion and risk management and evaluating patients' use of health services and their own engagement with their medical problems. The themes of ideas, concerns, and expectations of the biopsychosocial model of illness, and of communication, diagnostic, and negotiating skills run throughout these tasks. Papers in this issue of the BJGP illuminate and build on this approach to patient care, which is given a welcome and interesting new dimension by lan McKelvey, who describes The Consultation Hill (page 538), a persuasive account of a model to aid the teaching of consultation skills.

In terms of understanding illness presentation and of making a diagnosis, two important medical problems are highlighted chronic obstructive pulmonary disease (COPD) and urinary tract infection (UTI). COPD is the second most common cause of emergency department admission in inner cities and although the rise in incidence of the condition appears to have reached a plateau (Simpson et al page 483), the prevalence of COPD remains high, and the condition is still under diagnosed in primary care (Broekhuizen et al page 489). Patrick White (page 477) appeals to clinicians to seize the opportunities available to improve outcomes for patients with COPD by the use of new therapeutic agents and of pulmonary rehabilitation programmes.

The diagnosis of UTI in primary care remains controversial. While many clinicians rely on urine dipstick testing to rule infection in or out, Little's group (page 495) sounds a note of caution on existing clinical decision rules, and Alastair Hay (page 479) carefully sets this study and the use of urine culture in the context of the available research evidence.

In more challenging territory, two papers look at the involvement of primary care in patients with problems with drug misuse. Litchfield and colleagues (page 514) describe positive preliminary results of a clinic in Derby targeted at sex workers addicted to heroin, particularly important because continuing opiate dependency is one of the main factors keeping people in prostitution. The pioneering, GP-led service deserves to be replicated and further evaluated. Unfortunately, a Scottish survey of the involvement of GPs in the treatment of drug misusers over the last 8 years suggests that their level of engagement has fallen, perhaps due in part to the requirements of the present GP contract.

Many commentators have expressed concern about the limits on clinical practice imposed by an uncritical adherence to evidence-based medicine (EBM) and this debate has been fuelled by further concerns about the Quality and Outcomes Framework, within which only the measurable is measured and remunerated. Two articles this month add very usefully to the discussion. Joanne Reeve (page 521) asks us to move on from EBM and introduces us to Interpretive Medicine which 'represents an important shift in emphasis from the application of evidence in decision making to the generation of individual knowledge as a quality marker of generalist care'. This approach seems to have much to offer in the care of patients with complex needs - those with multiple disease comorbidities and with a web of personal, social, and psychological factors weighing on their management decisions - for which the evidence base may, in any case, be missing.

The important theme of the complexity of patient care and the frequently simplistic and one-dimensional solutions proposed to improve it are wittily and elegantly taken up in two allegorical commentaries by Simon Fraser (page 544), who returns to the timeless struggle at the gates of secondary care between the Gatekeeper and the Wizard, and Adrian Lamb (page 546), who introduces some new metaphors that are likely to have considerable currency, including the GP as locksmith and bomb disposal expert.

At the end of the day, how will we know whether we have done a good job? And how will we demonstrate that to others? Mike Pringle (page 475) has written a valuable position statement on the journey towards revalidation, and clearly we have some way to go. Whether the cost of the exercise, the inadequacies of the appraisal system, or something quite different made the Secretary of State pause for breath, it is of the utmost importance, above all for our patients and the public, that commitment to the assurance of good clinical practice by all doctors remains firmly on the agenda.

\section{Roger Jones}

Editor

\section{REFERENCE}

1. Stott NC, Davis R H. The exceptional potential in each primary care consultation. J R Coll Gen Pract 1979; 29(201): 201-205.

DOI: 10.3399/bjgp10X514675

C British Journal of General Practice 2010; 60: 473-552. 